\title{
Parental attitudes toward childhood obesity: Risky business
}

\author{
Patricia Grace-Farfaglia $^{1 *}$ and Lois S Peters ${ }^{2}$ \\ ${ }^{1}$ Lecturer, Nutritional Sciences, University of Connecticut, USA \\ ${ }^{2}$ Associate Professor, Enterprise Management and Organization, Rensselear Lally School of Management, USA
}

\begin{abstract}
Background: More than a third of children and adolescents are overweight or obese in the US. Our study aimed to find natural patterns of response to items on attitudes and beliefs about news media exposure, parental weight history, attitudes and beliefs about childhood obesity to uncover dimensions that best describe risk appraisal in parents of children under 13. We theorized that disease awareness advertising for health-related products and media reports on the child obesity epidemic may impact parent beliefs about childhood obesity and family lifestyle behaviors. The intent of this study was to provide a foundation for more effective communication regarding risk appraisal related to childhood obesity by health providers.
\end{abstract}

Methods: A pilot cross-sectional online survey of 250 parents with children ages 1-13 was completed in September 2005 through a market survey firm by consumer panel "opt-in" with a response rate of $23 \%$

Results: A discriminant analysis identified four risk segments or with different attitudes about the media coverage, disease awareness advertising, family and parent efficacy, technological efficacy, healthcare justice (procedural and interpersonal), and obesity risk appraisal. Our data suggests that healthcare justice has more impact on child obesity risk appraisal than media reports. Family efficacy was related to receiving healthcare justice from their health providers. Fathers had lower risk appraisal than mothers and received less healthcare justice from their child's provider. This study fills a gap in the literature on the impact of risk perception by the family decision maker and its effect on childhood obesity.

\section{Background}

Obesity has increased $30 \%$ among children since 1980 and at the time of this study the rate of increase shows no sign of decreasing $[1,2]$. Health researchers and advocacy groups have implicated the marketing practices of manufacturers of soda, cereals and fast food as a major driver in the growth of obesity $[3,4]$. Responding to these critics, the food industry has initiated various social marketing campaigns to promote exercise and healthier choices for school-age children. Nevertheless few US researchers have asked parents about their attitudes and beliefs toward obesity and their perception of their own child's weight status with notable exceptions [5-7].

Mounting evidence and pressure from consumers and food policy advocates have driven marketers make efforts to comply with proposed Federal restrictions on the promotion of low nutrition, obesogenic foods to children. Health policy solutions which focused on the restriction of advertising to children, however, lacked empirical evidence to support eliminating the marketing of food and beverage products to children [8]. Little has changed since 2005 as evidenced in two recent studies of advertising content in children's programming. These studies concluded that only $20 \%$ of ads for foods and beverages with added sugars targeted at children comply with proposed guidelines and continue to feature products of low nutritional quality $[9,10]$. Mass media attention to the child obesity connection to sugar sweetened beverages has yet to yield significant declines in consumption [11]. Social trends such as awareness of environmental health risks and subsequent changes in behavior (e.g. growth of fitness centers, growing interest in "natural products") suggested to us a need to shift messaging. Non-food advertising that highlights health and disease awareness could have a significant impact than recognized previously. A recent study examined the relationship between direct-to-consumer advertising (DTCA) of statin drugs during the period of our study on food and exercise guilt and self-worry [12]. The results of this study using OLS regression modeling which controlled for demographic variables typically used in marketing segmentation suggest that greater DTCA exposure is predictive of food and exercise guilt. Participants exposed to 150 or more ads experienced food guild 4 standard deviations above the lowest quartile of viewership. We theorized that parental attitudes about child obesity and its relationship to chronic disease risk were likely influenced by disease awareness messages from public service or pharmaceutical-sponsored advertising, as well as news media coverage of obesity. The time frame of our study was a peak period for promotion of DTCA through various media outlets, with television advertising spending in 2006 reaching its height of 3,270 million dollars [13].

A review of the literature failed to find evidence on the effects of non-food advertising on attitudes toward obesity health-related behaviors or attitudes. A recent database search identified an Australian study which exposed women over 45 years to print disease awareness advertising for weight loss products [14]. The researchers concluded that disease awareness messages had no significant effect on consumer intention to request a prescription, but consumers regarded commercial sponsored informational messages to be valuable. Researchers

Correspondence to: Patricia M Grace-Farfaglia, Department of Nutrition Sciences, University of Connecticut-Waterbury, 99 E. Main Street, Waterbury, CT, USA, Tel: 203-270-0097; Fax: 203-270-0097;E-mail:patricia.grace-farfaglia@uconn.edu

Key words: childhood obesity, parental attitudes, risk appraisal, efficacy, media, and advertising

Received: March 22, 2016; Accepted: April 11, 2016; Published: April 14, 2016 
proposed that exposure to DTCA ads for prescription drugs containing familial risk cues may impact the intention to either engage in healthy lifestyle behaviors, purchase the advertised medication, or belief in genetic determinism of health risk [15]. Experimental results showed that exposure to familial risk cues strengthened the intention to either engage in preventive behaviors or to purchase the advertised drug. It is not known whether mass media messages from news reports and DTCA and health-related disease awareness ads affect parental risk perception of family lifestyle choices that favor or prevent child obesity.

Children's media consumption is a robust factor for obesity risk through its association with fewer family meals and lack of outdoor play [16-18]. Longitudinal research from the Framingham study on the effects of media consumption on weight status reported that children in the highest television-watching group had the greatest gains in BMI from ages 4-11 years [19]. Low consumption of fruits, vegetables and milk was associated with higher BMI and greater percent body fat in a 12-year study of nutrition intake and body composition in children [20]. Authors of a systematic review concluded that giving sugar sweetened beverages (SSB) to children is associated with obesity, and another study reported that daily consumption SSB in infancy was predictive of consumption levels at age $6[21,22]$. Parental perception of risk is a key factor in preventing childhood obesity because it is related to their perception of the true weight status of their child [2325]. Family viewing time is primarily spent watching media in the later part of the day when self-control and food regulation resources may be depleted [26]. Direct-to-consumer drug ads on network programs appear more frequently during the afternoon and early-evening hours [27]. Experimental evidence supports the influence of time of day and media content on adult food consumption [28]. Lifestyle messages serve to prime a viewer's health goals, but pharmaceutical health awareness advertising may distract the viewer from nutrition and lifestyle related intentions. Media messages featuring healthy foods act as a prime for individual's intentions to act with greater self-control concerning food choices. But one qualitative study found that interpretation of these messages can be highly flawed causing parents to reject evidence-based recommendations, such as sharing family meals or eating breakfast [29]. The effect of health awareness advertising on individual disease susceptibility conclusions may be skewed toward lowering threat because the focus is often on symptom relief and risk avoidance from use of a product, not lifestyle practices. In one study 241 women were asked about susceptibility to disease after exposure to disease awareness advertisements by different sponsors, and over half reported that they would go to their doctor and ask for a prescription drug [30].

When an individual is first presented with threatening information the message is likely to be discounted because optimism on the likelihood of one's ability to address a threat minimizes negative emotions, a response known as fear control, a maladaptive response [31]. This effect is salient to childhood obesity as the media's portrayal of parents of obese children is framed with blame and stigmatizes their parenting rather than offering solutions to the problem [32]. Roger's Protection Motivation Theory first proposed that the effect of a fear appeal depends on the individual's ability to address the health threat or self-efficacy [33]. Later, Witte expanded upon this theory to explain the relationship between threat and efficacy [34]. The extended parallel process model (EPPM) further develops our understanding of the mechanisms underlying the cognitive and affective appraisal of threatening messages and behavioral responses such as fear and danger control [35].

The brief office encounter with a pediatrician during a well-child visit where body mass index (BMI) is discussed is an important initiator of health intervention. But, it is likely to trigger negative emotions and protective responses in the parent, such as denial of the problem or distrust in the science behind the diagnosis. The pediatric visit serves to help parents of overweight children correct their "healthy" perception of their child weight and participate in weight management programs in the community [36,37]. A parent's media exposure, prior beliefs, and attitudes may determine their risk appraisal [38]. In this context, risk clarification may influence parental choices and their acceptance of health counseling.

Intent of this exploratory study was to find natural patterns of responses to items on media attitudes and parental efficacy beliefs about childhood obesity. This study was an inquiry into the determinants (media use, efficacies, and justice perceptions) of adaptive and maladaptive coping responses to a childhood health threat. The authors used these characteristics to better define factors of fear appeal success or failure for different cohorts of parents to inform health intervention communications.

The authors sought to answer the following questions:

1) Does media coverage of child obesity have an effect on risk appraisal?

2) Is there a relationship between disease awareness messages and risk appraisal?

3) Does perceived injustice in healthcare encounters have an effect on health risk appraisal?

4) What role do family efficacy beliefs play in risk appraisal?

\section{Methods}

A cross-sectional online survey of parents of children ages 1-13 was completed in September 2005 through a market survey firm by consumer panel "opt-in". The online survey host monitored survey participation to insure delivery of the desired demographics. A random sample of panel members was invited to respond to a "Family Health" survey. The study protocol for human subjects was approved by Rensselear Institutional Review Board. Personal resources funded this project. The "Family Health" survey is a comprehensive questionnaire on attitudes and beliefs about risk perceptions regarding childhood obesity, weight history, media exposure, and demographics. Most of the survey items were based on reliable scales. The Family Health Survey consisted of the following constructs that are theorized to predict risk appraisal. The proposed Risk Appraisal Model (RAM) appears in Figure 1.

\section{Latent variables}

Risk appraisal is a protective mechanism to control fear or address danger from a health threat. It is comprised of two components: selfefficacy and threat perception. Self-efficacy, or in this case parental self-efficacy, is the awareness of one's ability to control actions and their outcomes. It is characterized by human agency, personal control and perceived competence. An individual who has a sense of reduced self-efficacy will be more likely to expect failure and is less likely to persist in striving for challenging goals. Threat perception is comprised of two components: perceived susceptibility and perceived severity to the threat. Risk attenuation is the reduction of the threat posed by the hazard which varies with individual characteristics, beliefs, and attitudes toward obesity. The dependent variable, risk appraisal, was modified from fear and danger control subscales previously published 


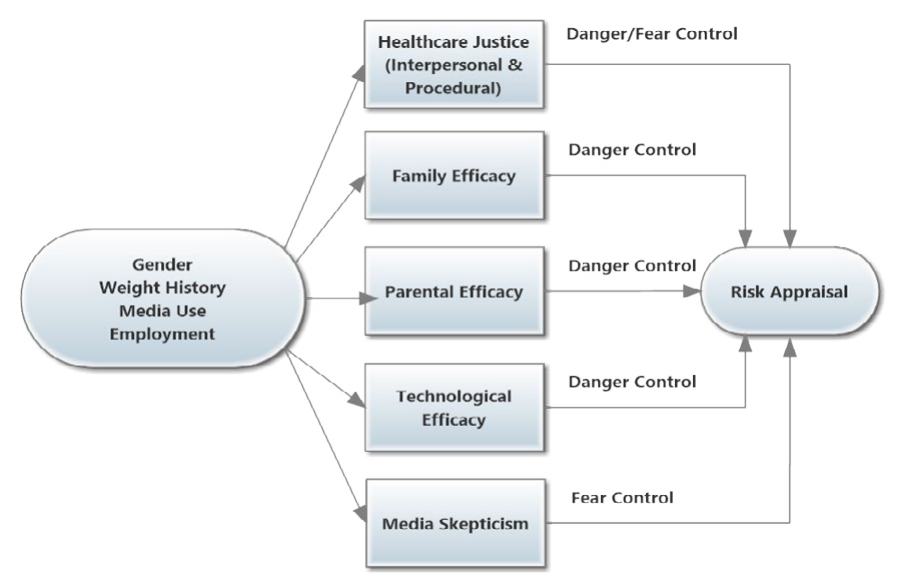

Figure 1. Risk Appraisal Model (RAM). Danger control is a condition of high fear and high efficacy, while fear control is a state of high fear and low efficacy.

and validated [35]. Respondents indicated the degree to which they agree or disagree with statements on a seven point scale for their belief that childhood obesity has serious consequences, is extremely harmful to health, likelihood that their child will become obese, the risk that their child will become obese or is at risk of developing obesity, and if they were afraid that their child will become obese.

Media skepticism may also be important in understanding the attenuation of risk. Parents may detect a media bias against overweight people and reject the notion of an obesity epidemic. Scales have been validated for the attitudes toward news coverage of the genetic modification of foods issues were modified for health-awareness advertising [39].

Advertising attitudes for pharmaceutical marketing messages may be related to the attenuation of risk. Items were developed that conceptually covered the domains of accuracy, credibility, and fear response. As a scale they produced low reliability. One item was more predictive of threat and efficacy, and that detected bias in the credibility of drug ads.

Relational and procedural social justice occurs when consumers perceive fairness in service encounters, they believe that the health organization or its representatives make decisions based on valid and non-biased procedures and information [40]. Healthcare consumers have an expectation that decisions are fairly applied to all patients. The concept of "behavioral justice" has been termed to address the tension between an individual's level of control over obesity and being held responsibility for health behaviors [41]. Although health providers have the collective right to attach labels to people, some diagnoses may result in stigmatization. When a child is assigned to a category which the parent shares the same social identification, the parent may experience emotions and behavioral tendencies similar to victims of abuse $[42,43]$. Procedural and interpersonal justice items were modified from reliable scales used to predict illness in the organizational setting and relabeled healthcare justice [44].

An evaluation of the potential effect of technological efficacy was explored. It was thought that the increased certainty from genetic testing for obesity related genes and chronic disease may increase the threat from media reports. Since that time the use of nutrigenomics for health counseling has become more commonplace, but awareness by the public was limited at the time. The survey items for latent variables are located in Appendix A (Supplemental Materials).
Family efficacy is a form of collective efficacy where members believe in the family's capabilities to perform tasks and achieve goals necessary for family functioning [45]. The Perceived Collective Family Self-Efficacy Scale was selected for this measure [46]. Family and parental efficacy subscales were expanded to isolate collective and individual effects.

\section{Independent variables}

Family weight history and feelings of discrimination by others in society may result in parenting that is either laissez-faire about nutritional choices or highly restrictive. An environment that favors foods with high caloric density reduces a child's ability to self-regulate energy intake in response to daily changes from physical activity and growth demands [23,47]. Two four item scales asked parents about their weight history and perceptions of their child's weight status at four different periods: infancy, toddler, early childhood and adolescence.

Employment for young parents has initiated many changes in family lifestyles and earning power in the past 30 years. But, women often have more responsibility for household functions than their partners, regardless of employment demands. This effort-reward imbalance at work or at home can create the conditions for poor family health [48]. A relationship between rising cumulative body weight in children has been observed due to the employment intensity of dualearner households [49]. Participants were asked questions on age, gender, and occupation.

Media use measures the frequency of exposure to advertising messages about the role of diet and health. Pharmaceutical companies specifically target adults during the early afternoon television broadcasts and news broadcasts [50]. A four item scale was developed to determine the frequency and time of exposure to health awareness advertising. Parents were asked to rank different media sources of health information they were likely to use.

An invitation to respond to a survey on family health issues with a human subjects consent form. Participants will receive 50 points redeemed through an online catalogue of products and charitable contributions. Panelists were free to accept or decline this offer. Panelists who declined to participate remained eligible for monthly drawings for cash prizes. Survey data was transferred to the researcher by secure download from the site under password protection.

\section{Results}

The recruitment plan was to enroll 250 participants, but due to the need to balance demographic characteristics the final sample was 324 for a response rate of $23 \%$. Sample characteristics are provided in Table 1. Raw data was reviewed for participant terminations, gender composition, missing data, and item distribution characteristics. Of those that opted-in to the survey, 314 completed and 10 droppedout during the survey. Visual inspection of these cases indicated that two volunteers did not have a child under the age of 13, and the rest ended the survey at various points in the survey with no clear pattern to explain their withdrawal.

Principal components factoring with rotation was used to identify latent variables and their components. The screen test was inspected to determine the important factors with an eigenvalue greater than 1. Zero-order correlations of the predictor and outcome variables were inspected for significant associations. Cronbach's alphas were calculated for the composite variables within the model with the expectation that the internal consistency was an alpha of 0.79 or 
Table 1. Participant demographic characteristics.

\begin{tabular}{|l|c|}
\hline Demographic Variables & Distribution (n=324) \\
\hline Race (Percent) & 3.4 \\
Asian & 4 \\
Black/African American & 4 \\
Hispanic/Latino & 0.6 \\
Mixed Race & 0.3 \\
Native American & 0.6 \\
Other, Please Specify & 82.4 \\
White/Caucasian & 1.2 \\
Prefer not to answer & \\
\hline Parent Gender & $58(17.9 \%)$ \\
Male & $255(78.7 \%)$ \\
Female & \\
\hline Child Gender & $138(42.6 \%)$ \\
Male & $130(40.1 \%)$ \\
Female & \\
\hline Employment Status & $123(49.2 \%)$ \\
Employed & $99(39.6 \%)$ \\
Homemaker & $14(5.6 \%)$ \\
Student & $14(5.6 \%)$ \\
Retired & \\
\hline Education & $48(14.8 \%)$ \\
Advanced degree (Masters/PhD) & $12(3.7 \%)$ \\
Attended graduate school & $79(24.4 \%)$ \\
Graduated college/bachelor degree & $56(17.3 \%)$ \\
High school & $104(32.1 \%)$ \\
Some college or associate degree & $14(4.3 \%)$ \\
Trade/technical school &
\end{tabular}

greater. The scree plot from the analysis of the pilot study indicated that 7 factors would best describe the data. Principal components analysis was used because the primary purpose of the study was to identify and compute composite scores for the factors underlying parental risk appraisal. Initial Eigen values indicated that the first four factors explained $43.23 \% \%$ of the variance. The fifth and sixth factors had Eigen values of approximately 4.0 , and each explained only $2 \%$ of the variance. Factor scores based on Varimax rotation were generated and saved for all respondents. The factors that emerged were Risk Appraisal $(\alpha=0.846)$, Family Efficacy $(\alpha=0.940)$, Interpersonal Justice $(\alpha=0.916)$, Procedural Justice ( $\alpha=0.794)$, Technological Efficacy $(\alpha=0.823)$, Media Skepticism $(\alpha=0.753)$, and Advertising Skepticism $(\alpha=0.550)$. The disease advertising skepticism scales did not produce reliable factors and were reevaluated through inspection of zero-order correlation with risk appraisal. In general, the drug advertising attitude items had small correlations with risk appraisal. Overall, the ability to be skeptical of the motives of commercial advertising did not have a significant impact on risk appraisal. A cluster analysis the four factor scores were used as cluster start points in a K-Means cluster analysis. This procedure starts with a value for the initial center of all clusters, and then iteratively updates the location of the cluster center until the cluster center converges on a stable value. Individual observations are then assigned to the cluster whose center is closest to the observation's values on the clustering variables. A discriminant analysis was performed, but with only the 39 significant original variables as predictors. Our analysis provides information about the difference between a single cluster and all the observations not in the cluster to identify unique characteristics of the cluster. To do this, 4 dummy variables were made up, one for each group. These "0-1" group variables were then used as the independent variable in the t-tests. The stepwise procedure selected these variables in order of decreasing ability to discriminate among the cluster groups. The analysis indicates that only 39 of the original questionnaire items are needed to discriminate among the final clusters at a $94.8 \%$ accuracy level. One-way ANOVAs with the cluster number as independent variable and each of the original questionnaire values as dependent variables were conducted, with a Scheffé post-hoc test to determine groupings of clusters that differed significantly on each of the original variables. The ANOVA table is presented in Table 2.

The emergence of four segments of parents from the data differed significantly on their levels of responses to the threat of childhood obesity. Only $5.2 \%$ of respondents were not familiar with the topic of childhood obesity, with $60.8 \%$ were at least somewhat familiar and $33.6 \%$ were very familiar with the topic. Descriptive statistics for Family Health Survey scale factors are shown in Table 3 . The summated scales for the hypothetical factors that were measured had acceptable reliability greater than 0.75 .

The correlation matrix in Table 4 shows the association between group membership and the theoretical constructs risk appraisal, parental efficacy, family efficacy, media skepticism, and healthcare justice (procedural and interpersonal). The parents in group 1 are more likely to believe that the risk of obesity to their child is low, but admittedly they have less of an ability to control this risk. Group 2 as a target population presents a difficult mindset to change through an obesity intervention or informational campaign because these parents feel that their child has low risk for obesity. In addition, the parents express that they have a feeling of bias in their healthcare interactions, and regrettably have fewer skills and family support to address childhood obesity if it should arise. Group 3 parents balance a higher level of fear with greater resources to avoid or address the problem. Lastly, group 4 parents have higher family efficacy beliefs, but feel their child has low risk. Each group represents a profile to develop messages that address this imbalance between risk acceptance and family efficacy to avoid or redress environmental influences on childhood obesity.

Table 2. One-Way Analysis of Variance of clusters by theoretical constructs

\begin{tabular}{|l|c|c|c|c|c|c|}
\hline Construct & $\begin{array}{c}\text { Cluster Mean } \\
\text { Square }\end{array}$ & $\boldsymbol{d f}$ & $\begin{array}{c}\text { Error Mean } \\
\text { Square }\end{array}$ & $\boldsymbol{d f}$ & $\boldsymbol{F}$ & $\boldsymbol{p}$ \\
\hline Risk Appraisal & 82.708 & 3 & 27.569 & 244 & 35.539 & 0.000 \\
\hline Parental Efficacy & 23.747 & 3 & 7.916 & 245 & 15.503 & 0.000 \\
\hline Family Efficacy & 105.036 & 3 & 35.012 & 245 & 78.745 & 0.000 \\
\hline Interpersonal Justice & 160.495 & 3 & 53.498 & 245 & 126.43 & 0.000 \\
\hline Procedural Justice & 150.107 & 3 & 50.036 & 245 & 94.503 & 0.000 \\
\hline Technological Efficacy & 197.098 & 3 & 65.699 & 245 & 65.969 & 0.000 \\
\hline Media Skepticism & 2.07 & 3 & 0.690 & 245 & 1.225 & 0.301 \\
\hline
\end{tabular}

Table 3. Descriptive statistics for Family Health Survey scale factors.

\begin{tabular}{|l|c|c|c|c|c|}
\hline Factors & $\begin{array}{c}\text { No. of } \\
\text { items }\end{array}$ & M(SD) & Skewness & Kurtosis & Cronbach's $\alpha$ \\
\hline Risk Appraisal & 7 & $5.35(0.49)$ & -0.175 & -0.235 & 0.822 \\
\hline Parental Efficacy & 6 & $5.93(0.95)$ & -0.832 & 0.571 & 0.876 \\
\hline Family Efficacy & 13 & $5.49(0.93)$ & -0.240 & -0.704 & 0.940 \\
\hline Interpersonal Justice & 6 & $5.67(1.02)$ & -0.678 & 0.134 & 0.916 \\
\hline Procedural Justice & 5 & $5.19(1.01)$ & -0.218 & 0.514 & 0.720 \\
\hline Technological Efficacy & 8 & $4.93(.975)$ & .0150 & 0.334 & 0.799 \\
\hline Media Skepticism & 5 & $3.44(.990)$ & 0.270 & 0.153 & 0.755 \\
\hline
\end{tabular}

Table 4. Correlation between Groups and Factors.

\begin{tabular}{|l|c|c|c|c|}
\hline Variable & Group 1 & Group 2 & Group 3 & Group 4 \\
\hline Risk Appraisal & $-0.202^{* *}$ & $-0.273^{* *}$ & $-0.133^{*}$ & $-0.134 *$ \\
\hline Parental Efficacy & $-0.128^{*}$ & -0.038 & $0.179 * *$ & -0.019 \\
\hline Family Efficacy & $-0.128^{*}$ & $-0.179 * *$ & -0.002 & 0.003 \\
\hline Procedural Justice & $0.419 * *$ & $-0.181 * *$ & 0.024 & -0.066 \\
\hline Interpersonal Justice & $0.512^{* *}$ & $-0.132^{*}$ & 0.071 & 0.076 \\
\hline Technological Efficacy & $0.123^{*}$ & $-0.193 * *$ & -0.076 & $-.258^{* *}$ \\
\hline Media Skepticism & 0.063 & 0.003 & 0.064 & -0.002 \\
\hline
\end{tabular}


A Kruskal-Wallis $\mathrm{H}$ test showed a statistically significant difference in risk appraisal between the four groups, $\chi^{2}(3, N=247)=67.71, p$ $=0.000$, with a mean rank for risk appraisal of 102.79 for Group 1, 69.47 for Group 2, 153.18 for Group 3, and 161.46 for Group 4. The distribution in each cluster, although not shown in Table 4, is the similar across all racial categories $(\mathrm{p}=.952)$ identified in Table 1 . The average risk appraisal score was highest in Group 3 compared to other groups, $\mathrm{t}(246)=6.13, \mathrm{p}<.000,(95 \% \mathrm{CI} .729,1.12)$.

Cross-sectional studies have concluded that parental employment remains a formidable determinant of childhood obesity $[49,51,52]$. Our study shows a significant effect for employment, with unemployed parents having higher parental self-efficacy scores compared to those who are employed, $\mathrm{t}(218)=2.301, \mathrm{p}<.022$ (95\% CI -6.38, -0.492). Parents in Group 3 show the greatest, and Group 2 shows the lowest efficacy.

Our data suggests that for some parents the results of genetic testing may provide more certainty of their family's health risks. There was a significant difference in group means for the questions "I would take advantage of genetic testing and screening for obesity even before the development of definitive treatment or preventive measures" and "I would take advantage of genetic testing to gain information that would help me shape environmental influences on my children," $t(265)=$ $32.30, \mathrm{p}<.000$, and $\mathrm{t}(265)=37.32, \mathrm{p}<.000$, respectively. In comparison to the groups identified, group 3 is the most likely to use genetic testing for health-related decisions. This makes sense theoretically because this group favors danger control over fear control, and has the highest confidence in healthcare justice. The results for the group comparisons are located in Table 5 and 6 . The data suggests that parents in group 4, who have high efficacy, believe their children have lower risk for obesity. These respondents were the least likely to seek genetic testing for disease risk assessment. In addition, the more parents trusted the reliability of health testing, the more they believed that they would respond with risk reduction behaviors. As expected, group 3 parents were more likely to agree with the statement "Nutrition labels should include health risk information for high fat, salt, and sugar food products," $\mathrm{t}(132)=10.13, \mathrm{p}<.000,(95 \%$ CI 1.19, 1.76).

Overall, media skepticism had a small effect on risk appraisal. There was no significant difference between groups on media skepticism about news reports on the childhood obesity epidemic, $F(1,3)=.83$, p $>.05$. But there was a significant difference in response to commercially sponsored advertising between groups, $F(1,3)=2.64, \mathrm{p}=.05$. Parents in Group 3 responded more positively to disease awareness advertising than the other groups of parents, $F(1,3)=2.64, \mathrm{p}=.05$, and had also viewed them more frequently, $F(1,3)=3.896, p=.010$. This group was more likely to agree with the statement that "drug advertising helps me make better health decisions" $(\mu=4.51$, s.d. $=1.8, \mathrm{~F}(1,3)=6.449$, $\mathrm{p}=.000)$.

The perception of justice in health treatment is has a moderate association to risk appraisal. As shown in Table 7, there were moderate correlations between risk appraisal and the healthcare justice subscales: procedural $(\mathrm{r}=.467, \mathrm{p}=.000)$ and interpersonal $(\mathrm{r}=.357, \mathrm{p}=.000)$. Parent history of obesity was significantly associated with risk appraisal, $F(1,2)$

Table 5. One-way analysis of variance of groups by latent variables.

\begin{tabular}{|c|c|c|c|c|c|c|}
\hline & & Sum of Squares & df & Mean Square & $\mathbf{F}$ & Sig. \\
\hline \multirow[t]{3}{*}{ Risk Appraisal } & Between Groups & 421.56 & 3 & 14.052 & 29.035 & .000 \\
\hline & Within Groups & 117.606 & 243 & .484 & & \\
\hline & Total & 159.763 & 246 & & & \\
\hline \multirow[t]{3}{*}{ Family Efficacy } & Between Groups & 100.678 & 3 & 33.559 & 72.387 & .000 \\
\hline & Within Groups & 113.122 & 244 & .464 & & \\
\hline & Total & 213.800 & 247 & & & \\
\hline \multirow[t]{3}{*}{ Parental Efficacy } & Between Groups & 25.188 & 3 & 8.396 & 16.568 & .000 \\
\hline & Within Groups & 123.651 & 244 & .507 & & \\
\hline & Total & 148.838 & 247 & & & \\
\hline \multirow[t]{3}{*}{ Technological Efficacy } & Between Groups & 203.918 & 3 & 67.973 & 70.008 & .000 \\
\hline & Within Groups & 236.908 & 244 & .971 & & \\
\hline & Total & 440.826 & 247 & & & \\
\hline \multirow[t]{3}{*}{ Interpersonal Justice } & Between Groups & 160.226 & 3 & 53.409 & 125.516 & .000 \\
\hline & Within Groups & 103.825 & 244 & .426 & & \\
\hline & Total & 264.052 & 247 & & & \\
\hline \multirow[t]{3}{*}{ Procedural Justice } & Between Groups & 148.036 & 3 & 49.345 & 91.854 & .000 \\
\hline & Within Groups & 131.081 & 244 & .537 & & \\
\hline & Total & 279.117 & 247 & & & \\
\hline
\end{tabular}

Table 6. Group means for latent variables.

\begin{tabular}{|c|c|c|c|c|c|c|}
\hline & $\begin{array}{c}\text { Risk } \\
\text { Appraisal }\end{array}$ & $\begin{array}{l}\text { Family } \\
\text { Efficacy }\end{array}$ & $\begin{array}{l}\text { Parental } \\
\text { Efficacy }\end{array}$ & Technological Efficacy & $\begin{array}{c}\text { Interpersonal } \\
\text { Justice }\end{array}$ & $\begin{array}{c}\text { Procedural } \\
\text { Justice }\end{array}$ \\
\hline \multicolumn{7}{|l|}{ Group 1} \\
\hline $\operatorname{Mean}(\mathrm{SD})$ & $5.11(0.60)$ & $5.21(0.66)$ & $4.32(0.69)$ & $4.68(1.01)$ & $5.60(0.69)$ & $5.20(0.81)$ \\
\hline \multicolumn{7}{|l|}{ Group 2} \\
\hline Mean(SD) & $4.74(0.74)$ & $4.58(0.81)$ & $4.06(0.57)$ & $3.82(0.74)$ & $4.29(0.69)$ & $4.26(0.72)$ \\
\hline \multicolumn{7}{|l|}{ Group 3} \\
\hline Mean(SD) & $5.67(0.72)$ & $6.30(0.67)$ & $5.02(0.96)$ & $5.66(1.07)$ & $6.56(0.67)$ & $6.72(0.39)$ \\
\hline \multicolumn{7}{|l|}{ Group 4} \\
\hline $\operatorname{Mean}(\mathrm{SD})$ & $5.35(0.81)$ & $6.07(0.60)$ & $4.21(0.65)$ & $3.09(1.06)$ & $6.26(0.55)$ & $5.46(0.81)$ \\
\hline
\end{tabular}


Table 7. Correlation between factors

\begin{tabular}{|c|c|c|c|c|c|c|c|c|}
\hline Variable & SD & 1 & 2 & 3 & 4 & 5 & 6 & 6 \\
\hline 1. Risk Appraisal & $(0.8)$ & 1 & & & & & & \\
\hline 2. Family Efficacy & $(0.9)$ & $0.329 * *$ & 1 & & & & & \\
\hline 3. Parental Efficacy & $(0.9)$ & $0.445^{* *}$ & $0.497 * *$ & 1 & & & & \\
\hline 4. Interpersonal Justice & $(0.1)$ & $0.357^{* *}$ & $0.509^{* *}$ & $0.416^{* *}$ & 1 & & & \\
\hline 5.Technological Efficacy & $(1.0)$ & $0.123^{*}$ & $-0.193 * *$ & -0.076 & $-0.258 * *$ & 1 & & \\
\hline 6. Media Skepticism & $(1.0)$ & $-0.312^{* *}$ & -0.051 & $-0.155^{*}$ & -0.021 & -0.119 & 1 & \\
\hline 7. Procedural Justice & $(1.0)$ & $0.467 * *$ & $0.383^{* *}$ & $0.455^{* *}$ & $0.494 * *$ & $0.349^{* *}$ & -0.04 & 1 \\
\hline
\end{tabular}

Table 8. Correlation between weight perception of parent and child.

\begin{tabular}{|c|c|c|c|c|c|c|c|c|c|c|c|}
\hline Variable & SD & 1 & 2 & 3 & 4 & 5 & 6 & 7 & 8 & 9 & 10 \\
\hline 1. Parent (5-10 yrs) & $(1.0)$ & 1 & & & & & & & & & \\
\hline 2.Adolescence & (1.1) & $0.652 * *$ & 1 & & & & & & & & \\
\hline 3. 20 's & $(1.0)$ & $0.395 * *$ & $0.534 * *$ & 1 & & & & & & & \\
\hline 4. Present & (1.1) & $0.253^{* *}$ & $0.385^{* *}$ & $.611 * *$ & 1 & & & & & & \\
\hline 5. Child 1 yr & $(1.0)$ & $0.125^{*}$ & 0.113 & -0.029 & -0.041 & 1 & & & & & \\
\hline 6. Toddler & $(0.7)$ & $0.184 * *$ & $0.235^{* *}$ & 0.09 & 0.073 & $0.654 * *$ & 1 & & & & \\
\hline 7. Preschool & $(0.7)$ & $0.286^{* *}$ & $0.332 * *$ & 0.149 & $0.163^{*}$ & $0.342 * *$ & $0.766 * *$ & 1 & & & \\
\hline 8. K-2nd grade & $(0.8)$ & $0.239^{*}$ & $0.240^{*}$ & $0.227^{*}$ & 0.178 & 0.139 & $0.523 * *$ & $0.793 * *$ & 1 & & \\
\hline 9. 3-5th grade & $(0.9)$ & $0.424 * *$ & $0.450^{* *}$ & -0.075 & 0.095 & 0.204 & $0.430 * *$ & $0.578 * *$ & $0.747 * *$ & 1 & \\
\hline 10. Grades 6-8 & (1.1) & $0.416^{*}$ & $0.604 * *$ & 0.182 & 0.053 & 0.298 & $0.445^{*}$ & $0.528 * *$ & $0.548^{* *}$ & $0.859 * *$ & 1 \\
\hline \multicolumn{12}{|c|}{$\begin{array}{l}\text { Notes. ** Correlation is significant at the } 0.01 \text { level ( } 2 \text {-tailed). } \\
\text { * Correlation is significant at the } 0.05 \text { level ( } 2 \text {-tailed). } \\
\text { Mean age of child }=4.36 \text { yrs }(3.03), \mathrm{n}=236 \text {. }\end{array}$} \\
\hline
\end{tabular}

$=5.22, \mathrm{p}=.000$. Parents were asked about their body weight at different ages and their weight assessment of their child with a scale of 1 (very underweight) to 5 (very overweight). The mean age of the children of our respondents is $4.36 \mathrm{yrs}(\mathrm{n}=236$, SD 3.03). Correlations between parent perceptions of weight in Table 8 and shows a pattern of the parent's weight history being correlated with their assessment of their child's weight. This association suggests a role for the parent's memory of their own childhood weight with their child's weight (parent weight assessment during adolescence, $\mu=4.88$ (1.1), with child's weight grades $6-8, \mathrm{r}=.604, \mathrm{p}=.000, \mathrm{n}=266$ ). A parent with a history of overweight may feel the threat from the childhood obesity epidemic more keenly, and this was especially true if they were overweight teens and preteens.

In addition, there was a significant effect for child gender on parent efficacy, $t(264)=2.324, \mathrm{p}=.021,(95 \%$ CI $-0.067,-0.426)$ with parents of a male child reporting higher efficacy. Fathers felt they received less interpersonal justice from health providers than did mothers $\mathrm{t}(264)=$ $-2.728, \mathrm{p}=.007,(95 \%$ CI $-814,-.132)$.

There was a medium size association between family efficacy and risk appraisal $(\mathrm{r}=.329, \mathrm{p}=.000)$. The relationship between family efficacy and the healthcare justice subscales of moderate size and significance (interpersonal $\mathrm{r}=.51$ and procedural $.38, \mathrm{p}=.000$ ). This indicates that parents who have a supportive family receive better interpersonal and procedural justice, and this may make them feel more open to receiving health guidance. The parents in Group 2 responded with the lowest means for risk appraisal, efficacy in each area, and healthcare justice as seen in Table 4.

\section{Discussion}

Generalizability of these results is limited to parents of children under age 13 who are willing to respond to respond to surveys for small rewards such as points and drawings for prizes. The theoretical constructs had acceptable to good reliability. The next phase should include test-retest reliability to evaluate the stability of the instrument. Our attempt to develop a new construct, technological efficacy, could be strengthened through revision of the items with lower primary loadings and possibly adding new items as technology has changed in the intervening years. The instrument included items on the possibility that genetic counseling for genetic markers for cancer, diabetes, and heart disease would motivate parents to embrace lifestyle change. Nutrigenomic testing is an emerging trend in medical practice, although it has been popular in alternative and complementary medicine for several years. This survey predated widespread information on childhood obesity disseminated by public health campaigns such as "Let's Move" and "We Can." The need to intervene prior to pregnancy and the preschool years has been highlighted in recent studies, and health intervention efforts in early development will benefit the health of both parent and child [53-55].

Revisiting the data presented in this paper brought fresh insight into both commercial and health-related communications with the public. The question of who is listening is not only an academic one. Parents are being exposed to messages in the media, including news and prime-time programming featuring reality weight loss competitions. Pharmaceutical companies provide disease awareness not only on television, but have multimedia campaigns within social media, patient portals, and infomercials in physician offices. Group 1 parents believed that their child is at low risk, but also felt that they have little success if they had to address this problem. While group 4 had high efficacy, they also believed their child had low risk. This may demonstrate the presence of a "self-other" gap in their health consciousness dimension due to the individualistic outlook of Americans. This may cause parents to believe they are at lower obesity risk than others [56]. Group 3 parents recognized that their child was at risk and may be ready to 
make changes in the family lifestyle with a high level of efficacy. A generational effect may be underlying some of the threat perception as parents with a history of obesity were most likely to place their child at higher risk. Child obesity as a serious health concern for both children and adults, and employers are beginning to offer support in this area as part of health benefits. Coordination between school and worksite based wellness programs may support the entire family's health goals and reduce the feeling of bias felt by the parents in our study [57]. Large employers are looking at healthcare costs directly related to childhood obesity, such as lost work days and medical costs for caring for a child with chronic disease related to obesity [58]. This is another likely source of social risk amplification that was not addressed by this study is the promotion of childhood obesity services by health insurers [59].

What is clear from the parent responses to our survey is that educators and health practitioners need to amplify the potential risk of obesity for parents early in the developmental period. Access to child obesity services continues to be a barrier and the effectiveness of the promotion of those services to motivating parents to make lifestyle change is a major gap in the literature [59] The motivational interview is best able to identify risk perception and to support the acquisition of new eating and physical activity behaviors, but its effectiveness depends on the level of acculturation of the family and the communication styles of parent and health professional [60-62] . Parents must be encouraged to embrace health and lifestyle goals, not just prevent obesity in their children. Early intervention at all ages would be a direct consequence of getting healthcare justice. Parents will be more effective at managing their weight and their child's with the right balance between lifestyle and compassionate healthcare.

\section{Conclusion}

Understanding how the family decision maker perceives risk is important to achieving the realignment of product innovation, positioning, and market communications. Body mass index surveillance programs in schools must work closely with pediatricians and primary care providers to make an impact on the obesity epidemic among children. Health practitioners recognize that managing risk uncertainty, stigma, marginalization, justice, and family culture during health intervention communications with families is essential. Family support is an important factor for balancing school, work, and health demands. Our data suggest that there are gender differences in risk appraisal, as the difference between mother and father's risk perception may present a barrier to making changes within an obesogenic home eating environment.

Healthcare is more available today then in 2005 due to changes in government policy. The Federal government and healthcare providers should conduct cross-sectional studies that follow risk appraisal to get a global picture of how consumers are responding to health-related messages. Creating a clearer picture of the beliefs of parents and their families will help industry and provider groups create effective social and commercial marketing messages.

\section{References}

1. Ogden CL, Carroll MD, Kit BK, Flegal KM (2012) Prevalence of obesity and trends in body mass index among US children and adolescents, 1999-2010. JAMA 307: 483490. [Crossref]

2. Ogden CL, Carroll MD, Flegal KM (2008) High body mass index for age among US children and adolescents, 2003-2006. JAMA 299: 2401-2405. [Crossref]

3. McCarthy M (2014) Soda tax would have greatest effect on childhood obesity, US study finds. BMJ 349: g5456. [Crossref]
4. Schwartz M, Gerhard DM, Monsey MS (2014) Obesity: from public health to public policy: an interview with Marlene Schwartz, PhD. Yale J Biol Med 87: 167-71. [Crossref]

5. Goodell LS, Pierce MB, Bravo CM, Ferris AM (2008) Parental perceptions of overweight during early childhood. Qual Health Res 18: 1548-1555. [Crossref]

6. Moore LC, Harris CV, Bradlyn AS (2012) Exploring the relationship between parental concern and the management of childhood obesity. Matern Child Health J 16: 902-908. [Crossref]

7. Peyer KL, Welk G, Bailey-Davis L, Yang S, Kim JK (2015) Factors associated with parent concern for child weight and parenting behaviors. Child Obes 11: 269-74.

8. Zywicki TJ, Holt D, Ohlhausen MK (2004) Obesity and Advertising Policy. George Mason Law Review. p. 979-1011.

9. Hingle MD, Castonguay JS, Ambuel DA, Smith RM, Kunkel D (2015) Alignment of Children's Food Advertising With Proposed Federal Guidelines. Am J Prev Med 48 707-713. [Crossref]

10. Kunkel DL, Castonguay JS, Filer CR (2015) Evaluating Industry Self-Regulation of Food Marketing to Children. Am J Prev Med 49: 181-187. [Crossref]

11. Ford CN, Ng SW, Popkin BM (2016) Ten-year beverage intake trends among US preschool children: rapid declines between 2003 and 2010 but stagnancy in recent years. Pediatr Obes 11: 47-53. [Crossref]

12. Kruger C, Niederdeppe J, Byrne S, Avery RJ (2015) Effects of exposure to direct-toconsumer television advertising for statin drugs on food and exercise guilt. Patient Educ Couns 98: 1150-1155. [Crossref]

13. Kornfield R, Donohue J, Berndt ER, Alexander GC (2013) Promotion of prescription drugs to consumers and providers, 2001-2010. PLoS One 8: e55504. [Crossref]

14. Hall DV, Jones SC (2008) Australian consumer responses to DTCA and other pharmaceutical company sponsored advertisements. Aust N Z J Public Health 32: 471 8 .

15. 15. Shim M, Cappella JN, Lerman C 2010 Familial Risk Cues in Direct-to-Consumer Prescription Drug Advertisements: Impacts on Intentions to Adopt Healthy Lifestyles and Pharmaceutical Choices. Journal of Applied Communication Research 38: 230247.

16. Tiberio SS, Kerr DC, Capaldi DM, Pears KC, Kim HK, et al. (2014) Parental monitoring of children's media consumption: the long-term influences on body mass index in children. JAMA Pediatr 168: 414-421. [Crossref]

17. Gable S, Chang Y, Krull JL (2007) Television watching and frequency of family meals are predictive of overweight onset and persistence in a national sample of school-aged children. J Am Diet Assoc 107: 53-61. [Crossref]

18. Tremblay MS, Gray C, Babcock S (2015) Position Statement on Active Outdoor Play. Int J Environ Res Public Health 12: 6475-6505. [Crossref]

19. Proctor MH, Moore LL, Gao D, Cupples LA, Bradlee ML, et al. (2003) Television viewing and change in body fat from preschool to early adolescence: The Framingham Children's Study. Int J Obes Relat Metab Disord 27: 827-833. [Crossref]

20. Hasnain SR, Singer MR, Bradlee ML, Moore LL (2014) Beverage intake in early childhood and change in body fat from preschool to adolescence. Child Obes 10: 4249. [Crossref]

21. Malik VS, Schulze MB, Hu FB 2006 Intake of sugar-sweetened beverages and weight gain: a systematic review. Am J Clin Nutr 84: 274-88. [Crossref]

22. Park S, Pan L, Sherry B, Li R (2014) The association of sugar-sweetened beverage intake during infancy with sugar-sweetened beverage intake at 6 years of age. Pediatrics 134: S56-62. [Crossref]

23. Doolen J, Alpert PT, Miller SK (2009) Parental disconnect between perceived and actual weight status of children: a metasynthesis of the current research. J Am Acad Nurse Pract 21: 160-6.

24. Sylvetsky-Meni AC, Gillepsie SE, Hardy T, Welsh JA (2015) The impact of parents categorization of their own weight and their child's weight on healthy lifestyle promoting beliefs and practices. J Obes 307381 .

25. Katz DL (2015) Oblivobesity: looking over the overweight that parents keep overlooking. Child Obes 11:225-226. [Crossref]

26. Muraven M, Tice DM, Baumeister RF (1998) Self-control as limited resource: regulatory depletion patterns. J Pers Soc Psychol 74: 774-789. [Crossref]

27. Boulos R, Vikre EK, Oppenheimer S, Chang H, Kanarek RB (2012) ObesiTV: how 
television is influencing the obesity epidemic. Physiol Behav 107: 146-153. [Crossref]

28. Boland WA, Connell PM, Vallen B (2013) Time of day effects on the regulation of food consumption after activation of health goals. Appetite 70: 47-52. [Crossref]

29. Sigman-Grant M, Strom H, Olson B, Wengreen H, Krogstrand KS, et al. (2010) Qualitative evidence of the disconnect between intent and interpretation of common child obesity prevention messages. Forum for Family and Consumer Issues 15.

30. Hall D, Jones S, Iverson D 2011 Disease awareness advertising - women's intentions following exposure. Aust Fam Physician 40: 143-7. [Crossref]

31. Lench H, Levine L (2005) Effects of fear on risk and control judgements and memory: Implications for health promotion messages. Cogn Emot 19: 1049-1069.

32. Ritland R, Rodriguez L (2014) The influence of antiobesity media content on intention to eat healthily and exercise: a test of the ordered protection motivation theory. J Obes 2014: 954784. [Crossref]

33. Rogers RW (1975) A Protection Motivation Theory of Fear Appeals and Attitude Change. J Psychol 91: 93.

34. Witte K (1992) Putting the fear back into fear appeals: The extended parallel process model. Commun Monogr 59: 329-349.

35. Kocsi S, Demeter G, Fogas J, Erces D, Kaszaki J, et al. (2012) Central venous oxygen saturation is a good indicator of altered oxygen balance in isovolemic anemia. Acta Anaesthesiol Scand 56: 291-297. [Crossref]

36. Hernandez RG, Cheng TL, Serwint JR (2010) Parents' healthy weight perceptions and preferences regarding obesity counseling in preschoolers: pediatricians matter. Clin Pediatr (Phila) 49: 790-8.

37. Pinard CA, Hart MH, Hodgkins Y, Serrano EL, McFerren MM, et al. (2012) Smart choices for healthy families: a pilot study for the treatment of childhood obesity in lowincome families. Health Educ Behav 39: 433-445. [Crossref]

38. Liechty JM, Saltzman JA, Musaad SM, STRONG Kids Team (2015) Health literacy and parent attitudes about weight control for children. Appetite 91: 200-208. [Crossref]

39. Frewer LJ, Miles S, Marsh R (2002) The media and genetically modified foods: evidence in support of social amplification of risk. Risk Anal 22: 701-11. [Crossref]

40. 40. Smith AK, Bolton RN, Wagner J (1999) A Model of Customer Satisfaction with Service Encounters Involving Failure and Recovery. J Mark Res 36: 356-372.

41. Adler NE, Stewart J (2009) Reducing obesity: motivating action while not blaming the victim. Milbank $Q$ 87: 49-70. [Crossref]

42. Yzerbyt V, Dumont M, Wigboldus D, Gordijn E (2003) I feel for us: the impact of categorization and identification on emotions and action tendencies. Br J Soc Psychol 42: 533-549. [Crossref]

43. Smith ER (1999) Affective and cognitive implications of a group becoming part of the self: New models of predjudice and of the self-concept. In: Michael Hogg \& Dominic Abrams, editor. Social Identify and Social Cognition. Oxford: Blackwell. p. 183-196.

44. Elovainio M, Kivimaki M, Vahtera J (2002) Organizational justice: evidence of a new psychosocial predictor of health. Am J Public Health 92: 105-8. [Crossref]

45. Bandura A (2000) Exercise of human agency through collective efficacy. Curr Dir Psychol Sci 9: 75-78.
46. Caprara GVR, Camillo, Scabini, Eugenia, Barbaranelli, et al. (2004) Assessment of filial, parental, marital, and collective family efficacy beliefs. Eur J Psychol Assess 20: $247-261$.

47. Mrdjenovic G, Levitsky DA (2005) Children eat what they are served: the imprecise regulation of energy intake. Appetite 44: 273-282. [Crossref]

48. Siegrist J (1996) Adverse health effects of high-effort/low-reward conditions. J Occup Health Psychol 1: 27-41. [Crossref]

49. Morrissey TW (2013) Trajectories of growth in body mass index across childhood Associations with maternal and paternal employment. Soc Sci Med 95: 60-68. [Crossref]

50. Brownfield ED, Bernhardt JM, Phan JL, Williams MV, Parker RM (2004) Directto-consumer drug advertisements on network television: an exploration of quantity, frequency, and placement. J Health Commun 9: 491-497. [Crossref]

51. Anderson PM, Butcher KF, Levine PB (2003) Maternal employment and overweight children. J Health Econ 22: 477-504. [Crossref]

52. Miller DP, Han WJ (2008) Maternal nonstandard work schedules and adolescent overweight. Am J Public Health 98: 1495-1502. [Crossref]

53. Wojcicki JM, Heyman MB (2010) Let's Move-childhood obesity prevention from pregnancy and infancy onward. $N$ Engl J Med 362: 1457-1459. [Crossref]

54. Hagobian TA, Phelan S, Gorin AA, Phipps MG, Abrams B, Wing RR 2015 Effects of maternal lifestyle intervention during pregnancy on untreated partner weight: Results from fit for delivery study. Obesity (Silver Spring).

55. Lioret S, Betoko A, Forhan A, Charles MA, Heude B, et al. (2015) Dietary patterns track from infancy to preschool age: cross-sectional and longitudinal perspectives. $J$ Nutr 145: 775-782. [Crossref]

56. Sukki Y, Lalwani AK, Vargas P (2008) Not Me or Not Them?: The Role of Culture in Discrepant Effects of Health Communication on Self and Others. In: Angela Y. Lee, Soman D, editors. NA - Advances in Consumer Research. Duluth, MN: Association for Consumer Research. p. 737-738.

57. Katz DL, O'Connell M, Yeh MC, Nawaz H, Njike V, et al. (2005) Public health strategies for preventing and controlling overweight and obesity in school and worksite settings: a report on recommendations of the Task Force on Community Preventive Services. MMWR Recomm Rep 54(RR-10):1-12. [Crossref]

58. Sepulveda MJ, Tait F, Zimmerman E, Edington D (2010) Impact of childhood obesity on employers. Health Aff (Millwood) 29: 513-521. [Crossref]

59. Rask KJ, Gazmararian JA, Kohler SS, Hawley JN, Bogard J, et al. (2013) Designing insurance to promote use of childhood obesity prevention services. J Obes: 379513 [Crossref]

60. Woo Baidal JA, Price SN, Gonzalez-Suarez E, Gillman MW, Mitchell K, et al. (2013) Parental perceptions of a motivational interviewing-based pediatric obesity prevention intervention. Clin Pediatr (Phila) 52: 540-548. [Crossref]

61. Arellano-Morales L, Wood CM, Elder JP 2013 Acculturation among Latino primary caregivers and physician communication: receipt of advice regarding healthy lifestyle behaviors. J Community Health 38: 113-9.

62. Marley SC, Carbonneau K, Lockner D, Kibbe D, Trowbridge F (2011) Motivationa interviewing skills are positively associated with nutritionist self-efficacy. J Nutr Educ Behav 43: 28-34. [Crossref]

Copyright: (C2016 Grace-Farfaglia P. This is an open-access article distributed under the terms of the Creative Commons Attribution License, which permits unrestricted use, distribution, and reproduction in any medium, provided the original author and source are credited. 